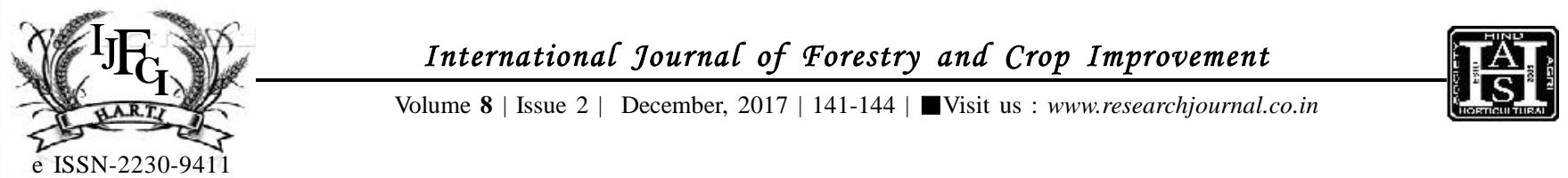

\title{
Study on the suitability of Lantana camara and Dendrocalamus strictus for the manufacturing of cement bonded particle board
}

\author{
MANish RANJAN, N. ISMITAAND SHWETABHATT
}

\begin{abstract}
Cement bonded wood composites have unique features due to their acceptability among industries. However the compatibility of cement with the wood species is always a major concern due to presence of wood extractive, which might have inhibitory effect on the bonding properties. In the proposed work cement particle boards were prepared using Lantana camara and Bamboo spp. (Dendrocalamus strictus) at three different ratios i.e. 2:1, 2.5:1 and 3:1. The soluble sugar and tannin content present in these species was estimated and their effect on the MOR of cement-lantana bonded boards and cement-bamboo bondedboards was studied. The modulus of rupture was less in case of bamboo boards with high soluble sugar content. Lantana boards performed better strength wise than bamboo boards.
\end{abstract}

KEY WORDS : Cement bonded particle boards, MOR, Tannin, Soluble sugar

HOW TO CITE THIS ARTICLE : Ranjan, Manish, Ismita, N. and Bhatt, Shweta (2017). Study on the suitability of Lantana camara and Dendrocalamus strictus for the manufacturing of cement bonded particle board. Internat. J. Forestry \& Crop Improv., 8 (2) : 141-144, DOI: 10.15740/HAS/IJFCI/8.2/141-144.

Article Chronical : Received : 20.10.2017; Revised : 11.11.2017; Accepted : 28.11.2017 